\title{
Imunocastração e ractopamina na qualidade de lombos suínos processados com sal e tripolifosfato
}

\author{
Andréia Fernanda Silva locca ${ }^{(1)}$, Daniel Silva Lucas $^{(2)}$, Daiane Aparecida Fausto(3), \\ Eduardo Francisquine Delgado ${ }^{(3)}$, Simone Fernanda Nedel Pértile ${ }^{(3)}$ e Natália Soares Janzantti ${ }^{(4)}$
}

\begin{abstract}
(1)Instituto Federal de Educação, Ciência e Tecnologia de Mato Grosso, Rodovia MT 235, Km 12, Zona Rural, Caixa Postal 100, CEP $78360-000$ Campo Novo do Parecis, MT, Brasil. E-mail: andreia.iocca@cnp.ifmt.edu.br (2)Universidade Federal Fluminense, Faculdade de Veterinária, Rua Vital Brasil Filho, no 64, Santa Rosa, CEP 24320-340 Niterói, RJ, Brasil. E-mail: danielucas_85@hotmail.com (3)Universidade de São Paulo, Escola Superior de Agricultura Luiz de Queiroz, Departamento de Zootecnia, Avenida Pádua Dias, no 11, CEP 13418-900 Piracicaba, SP, Brasil. E-mail: daianefausto@usp.br, efdelgado@usp.br, s.pertile@zootecnista.com.br (4)Universidade Estadual Paulista, Instituto de Biociências, Letras e Ciências Exatas, Rua Cristóvão Colombo, № 2,265, Jardim Nazareth, CEP 15054-000 São José do Rio Preto, SP, Brasil. E-mail: natalia@ibilce.unesp.br
\end{abstract}

Resumo - O objetivo deste trabalho foi avaliar o efeito da imunocastração e da suplementação com ractopamina na qualidade do lombo suíno processado com sal e tripolifosfato de sódio. Os tratamentos consistiram de condição sexual dos suínos (fêmeas, machos castrados fisicamente e imunocastrados) e suplementação ou não com ractopamina na dieta de terminação. Os cortes de lombos submetidos ao processamento com tripolifosfato de sódio e sal foram avaliados quanto aos parâmetros físico-químicos, microbiológicos e sensoriais. Não houve interação entre condição sexual e ractopamina nas características do lombo cru. A adição de ractopamina na dieta aumentou a força de cisalhamento dos lombos crus. Também não houve efeito da condição sexual nem da ractopamina na perda de peso por exsudação e no teor proteico dos lombos. Lombos de animais imunocastrados apresentaram menor perda de peso por cocção, enquanto lombos de animais não suplementados com ractopamina apresentaram maior umidade do que os dos suplementados. O processamento diminuiu a força de cisalhamento dos cortes, que foi menor nos animais imunocastrados sem suplementação com ractopamina. A imunocastração proporcionou lombos com altos valores de $a^{*}$ e L*. Diferenças na aparência e na textura dos lombos suínos, independentemente da condição sexual e da ractopamina, não são percebidas pelos consumidores, o que mostra que o processamento padroniza os cortes.

Termos para indexação: agonista $\beta$-adrenérgico, bem-estar animal, gonadotropina, marinação por injeção, qualidade de carne, tripolifosfato de sódio.

\section{Immunocastration and ractopamine in the quality of pork loin enhanced with salt and tripolyphosphate}

\begin{abstract}
The objective of this work was to evaluate the effect of immunocastration and supplementation with ractopamine in the quality of pork loin enhanced with salt and sodium tripolyphosphate. Treatments consisted of the sexual condition of the swine (females, physically castrated and immunocastrated males) and supplementation or not with ractopamine in finishing diet. The loins subjected to the enhancement with sodium tripolyphosphate and salt were evaluated as to physical-chemical, microbiological, and sensory parameters. There was no interaction between sexual condition and ractopamine on fresh pork loin characteristics. The addition of ractopamine in the diet increased the shear force in fresh loins. There was also no effect of sexual condition nor of ractopamine in purge loss and loin protein content. Loins of immunocastrated animals had less weight loss by cooking, whereas loins of animals non-supplemented with ractopamine showed higher moisture than those supplemented. Enhancement decreases the shear force of the cuts, which was lower in the immunocastrated animals without ractopamine supplementation. Immunocastration provided pork loins with high a* and L* values. Differences in the appearance and texture of pork loins, regardless of sexual condition and ractopamine, are not perceived by consumers, showing that enhancement standardizes the cuts.
\end{abstract}

Index terms: $\beta$-adrenergic agonist, animal welfare, gonadotropin, injection marinade, meat quality, sodium tripolyphosphate.

\section{Introdução}

A carne suína tem grande participação como matéria-prima em produtos cárneos e representa $75 \%$ da produção mundial destinada à industrialização. Preferida pelos europeus e pelos chineses, tem consumo superior a 40 e $37 \mathrm{~kg}$ per capita por ano, respectivamente 
(National Pork Board, 2014). No Brasil, o consumo da carne suína ainda é baixo, cerca de $15 \mathrm{~kg}$ per capita por ano, mas a produção nacional vem aumentando e está estimada em 3,7 milhões de toneladas para 2015 (Projeções do agronegócio, 2013), aquecida principalmente pelo aumento da população e pela demanda do mercado internacional.

Para acompanhar esse crescimento, a suinocultura utiliza novos modelos aplicados ao sistema de produção, por meio de melhoramento genético e nutrição, com destaque para as tecnologias da imunocastração e do uso de ractopamina. A imunocastração advém da demanda do mercado consumidor por alimentos de origem animal que atendam aos requisitos de bem-estar animal (Prunier et al., 2006) e é uma alternativa para a castração física sem anestesia. Os animais machos são mantidos inteiros até 8 semanas antes do abate quando recebem uma vacina que inibe o hormônio liberador de gonadotropina, o que reduz a secreção de compostos responsáveis pelo odor sexual. A ractopamina, um agonista $\beta$-adrenérgico análogo aos hormônios naturais catecolaminas, tem sido utilizada na alimentação de suínos como aditivo repartidor de energia, pelo aumento da síntese muscular (Rikard-Bell et al., 2009) e da lipólise.

A maioria dos estudos relacionados ao uso da ractopamina e à imunocastração em suínos trata dos efeitos destas tecnologias no desempenho zootécnico, na qualidade da carcaça e da carne suína (Xiong et al., 2006; Rikard-Bell et al., 2009; Hinson et al., 2011; Kutzler et al., 2011; Athayde et al., 2012; Caldara et al., 2013; Lanferdini et al., 2013). Os resultados obtidos mostram que a ractopamina é responsável pelo aumento da força de cisalhamento dos cortes (Xiong et al., 2006; Athayde et al., 2012), bem como pela diminuição dos parâmetros a* e b* de cor objetiva (Hinson et al., 2011; Athayde et al., 2012). Também há relatos de que o desempenho zootécnico dos suínos imunocastrados não é influenciado pela inclusão de ractopamina na dieta (Lanferdini et al., 2013), e que cortes de suínos imunocastrados apresentam atributos sensoriais e instrumentais semelhantes aos de machos castrados e de fêmeas (Rikard-Bell et al., 2009; Pauly et al., 2010). Essas alterações são relevantes, pois impactam tanto o mercado produtor quanto o consumidor.

O processamento por injeção é uma tecnologia correlata à marinação e já tem consumidores adeptos nos EUA, onde mais de $60 \%$ da carne suína consumida é submetida a esse procedimento. A técnica consiste em injetar uma solução de salmoura com baixa concentração de cloreto de sódio e fosfatos na carne crua, para aumentar a retenção de fluidos durante o cozimento do produto, a fim de aprimorar os atributos sensoriais, como suculência e maciez (Sheard et al., 1999). Poucos estudos são direcionados às possíveis alterações que o uso da ractopamina e a imunocastração de suínos causam na qualidade de produtos processados por injeção, como em presunto cozido (Fernández-Dueñas et al., 2008; Boler et al., 2011) e em bacon (Tavárez et al., 2012).

O objetivo deste trabalho foi avaliar o efeito da imunocastração e da suplementação com ractopamina na qualidade do lombo suíno processado com sal e tripolifosfato de sódio.

\section{Material e Métodos}

O estudo foi conduzido de abril a agosto, em duas granjas comerciais: a primeira, responsável pela cria e pela recria, está localizada na cidade de Itu, SP $\left(23^{\circ} 15^{\prime} 51^{\prime \prime} \mathrm{S}, 4^{\circ} 17^{\prime} 57^{\prime \prime} \mathrm{W}\right.$, a $583 \mathrm{~m}$ de altitude); e a segunda, responsável pela fase de terminação, está localizada a $300 \mathrm{~km}$ de distância, na cidade de Fartura, SP $\left(23^{\circ} 23^{\prime} 18^{\prime \prime S}, 4^{\circ} 30^{\prime} 36^{\prime \prime} \mathrm{W}\right.$, a $516 \mathrm{~m}$ altitude). Os procedimentos seguiram os protocolos aprovados pelo Comitê de Ética de Experimentação com Animais (CEUA 03/2012) e com Seres Humanos (CEP 0028.0.147.000-10) da Universidade Estadual de Campinas (Unicamp). Foram selecionados 450 leitões, machos $(\mathrm{n}=300)$ e fêmeas $(\mathrm{n}=150)$, de híbridos comerciais da genética Topigs (Tempo, macho $\mathrm{x}$ Topigs 40, fêmea), com até 1 dia de vida. $\mathrm{Na}$ fase maternidade ( 0 a 21 dias de vida), metade dos suínos machos foi castrada fisicamente sem anestesia aos 5 dias de vida ( $\mathrm{n}=150)$, e a outra metade foi mantida como suíno não castrado; já as fêmeas foram mantidas intactas. Ao atingirem 70 dias de vida, os animais foram transferidos para a segunda granja, onde permaneceram até a fase de terminação ( 70 a 175 dias de vida). Os machos não castrados fisicamente foram submetidos à imunocastração $(\mathrm{n}=150)$, por meio de duas doses de 2,0 $\mathrm{mL}$ da vacina Vivax (Zoetis, São Paulo, SP), aplicadas de 8 a 4 semanas antes do abate. Nesta mesma fase, foram incluídos 7,5 ppm da ractopamina Ractosuin (Ourofino Saúde Animal, Cravinhos, SP) na ração convencional à base de milho e soja, formulada 
com $16 \%$ de proteína e $0,91 \%$ de lisina, fornecida para metade dos animais (fêmeas, castrados fisicamente e imunocastrados) durante 21 dias ( \pm 2 dias) antes do abate. Dessa forma, os animais foram agrupados por condição sexual - fêmeas (FE), castrados fisicamente (CF) e imunocastrados (IM) - e submetidos à dieta com ractopamina (RAC) e à dieta controle $(\mathrm{CON})$ na fase de terminação, o que totalizou seis tratamentos: FE-RAC, FE-CON, CF-RAC, CF-CON, IM-RAC e IM-CON.

A condução dos animais e a técnica de abate utilizada seguiram os padrões de abate humanitário adotados comercialmente por um frigorífico brasileiro registrado no Serviço de Inspeção Federal (SIF 1758). Os suínos foram abatidos quando atingiram peso médio de $115 \mathrm{~kg}$, o peso comercial para abate. O jejum pré-abate adotado consistiu de 12 horas na granja e de 4 a 6 horas no abatedouro do frigorífico.

Com base no peso médio comercial da carcaça quente adotado para a região Sudeste, na espessura de toucinho e na profundidade de músculo, avaliados por instrumentação óptica de tipificação eletrônica "hennessy grading probe" (Hennessy Grading Systems, Auckland, Nova Zelândia), foram selecionados cinco suínos de cada tratamento. Utilizou-se como unidade experimental o lombo (músculo longissimus dorsi) de cada animal, compreendido entre a primeira vértebra torácica e a sexta vértebra lombar de meia carcaça suína direita, retirado após 24 horas de resfriamento da carcaça a $2^{\circ} \mathrm{C}$. Os lombos desossados foram embalados a vácuo, congelados rapidamente a $-31^{\circ} \mathrm{C}$, em túnel, e armazenados sob congelamento a $-30^{\circ} \mathrm{C}$, até posterior processamento.

O processamento por injeção foi realizado em sala climatizada até $12^{\circ} \mathrm{C}$. Os ingredientes utilizados na formulação da salmoura de injeção foram: tripolifosfato de sódio $\left(\mathrm{Na}_{5} \mathrm{P}_{3} \mathrm{O}_{10}\right)$, com peso molecular de 367,9, INS E451i, (Thermphos International B.V., Ritthem, Holanda), para $0,45 \%$ no produto final; e sal comum $(\mathrm{NaCl})$, para $0,75 \%$ no produto final. Os ingredientes foram pesados individualmente, misturados à água, à temperatura máxima de $4^{\circ} \mathrm{C}$, sob agitação mecânica contínua, dentro do reservatório da injetora.

Os lombos desossados de cada tratamento foram descongelados em câmara fria de $6^{\circ} \mathrm{C}$, por 48 horas, e pesados. Em seguida, foi injetada a solução de salmoura, equivalente a cerca de $10 \%$ do peso inicial do lombo, com o auxílio de injetora de 72 agulhas, com
3,00 mm de diâmetro modelo AMF300 (Intermec Ind., São Caetano do Sul, SP), ajustada para $206,8 \mathrm{kPa}$ de pressão; também foi realizado o massageamento do lombo em máquina de massagem para carne tumbler massageador (Frigomaq, Chapecó, SC) a vácuo (10 por $15 \mathrm{rpm})$. Novamente, os lombos foram pesados para determinar a percentagem de rendimento de injeção.

Após o processamento por injeção, os lombos de cada tratamento foram cortados em três partes, pesados, embalados a vácuo, codificados e armazenados por 72 horas, em câmara fria a $2^{\circ} \mathrm{C} \pm 1$, para equalização. Após esse período, as amostras foram armazenadas a $4^{\circ} \mathrm{C} \pm 1$ para posterior realização das análises.

Os lombos suínos de cada tratamento antes e após o processamento foram avaliados quanto a composição centesimal (umidade, proteínas e lipídeos), de acordo com o protocolo descrito pela Association of Official Analytical Chemists (1995); e pH, determinado por pHmetro, modelo DM-21 (Digimed Instrumentação Analítica, Campo Grande, SP), com eletrodo de punção direta.

A perda de peso por exsudação (PPE) foi determinada pela diferença de peso de cada uma das partes dos lombos suínos de cada tratamento, antes e após o processamento, seguindo Honikel (1987).

A perda de peso por cocção (PPC) foi obtida por meio da pesagem de cinco bifes de $2,5 \mathrm{~cm}$ do lombo de cada tratamento, antes e após a cocção em chapa elétrica pré-aquecida a $220^{\circ} \mathrm{C}$, até atingirem temperatura interna de $72,5^{\circ} \mathrm{C}$. Também foi avaliada a cor nos mesmos cinco bifes, expostos ao ambiente por 15 min antes da análise, mensurada em três pontos aleatórios. As leituras foram feitas pelo sistema CIE Lab, em que: $L^{*}$ representa a luminosidade; $a^{*}$ é o eixo verde-vermelho; e b* é o eixo azul-amarelo. Para isso, utilizou-se o colorímetro portátil Minolta Chroma Meter CR-200b (Konica Minolta, Osaka, Japão), com iluminante D65, ângulo de observação $10^{\circ} \mathrm{e}$ calibração com azulejo branco, para obtenção do ângulo de tonalidade (matiz) e do índice de saturação (croma), conforme as equações: matiz $=\tan ^{-1}\left(b^{*} / a^{*}\right)$; e croma $=\left[\left(a^{*}\right)^{2}+\left(b^{*}\right)^{2}\right]^{0,5}$.

Também foi realizada análise de textura instrumental por força de cisalhamento em amostras obtidas dos bifes grelhados, acondicionadas em cilindros de $1,27 \mathrm{~cm}$ de diâmetro, com uso do equipamento TA-XT2i (Stable Micro Systems Ltd., Surrey, Inglaterra) e do probe Warner Bratzler. O equipamento foi calibrado 
com peso padrão rastreável de $5 \mathrm{~kg}$. A velocidade de descida do dispositivo foi de $2 \mathrm{~mm} \mathrm{~s}^{-1}$. A determinação foi realizada sob temperatura ambiente de $25^{\circ} \mathrm{C}$, tendose considerado como valor final a média das leituras ( $\mathrm{n}=5$ por tratamento) expressas em $\mathrm{kgf} \mathrm{cm}^{-2}$.

Foram feitas análises para detectar a presença ou a ausência de Salmonella sp. em $25 \mathrm{~g}$ das amostras e de coliformes termotolerantes a $45^{\circ} \mathrm{C} \mathrm{g}^{-1}$, com tolerância de contagem a $10^{4}$, além da contagem de estafilococos coagulase positiva, nos lombos de cada tratamento e nos controles, de acordo com a resolução RDC no 12 da Agência Nacional de Vigilância Sanitária (Agência Nacional de Vigilância Sanitária, 2001) para o grupo de alimentos carnes cruas preparadas, de bovinos, suínos e outros mamíferos, refrigeradas ou congeladas, temperadas. As análises foram realizadas para garantir a segurança microbiológica dos tratamentos, para posterior análise sensorial.

O lombo suíno referente aos seis tratamentos, antes e após ser grelhado, foi utilizado para avaliação sensorial por 31 consumidores regulares de carne suína, de idade entre 21 e 58 anos, estudantes de graduação de Engenharia de Alimentos na Unicamp e funcionários do Instituto de Tecnologia em Alimentos, Campinas, SP. Inicialmente, foi avaliada a aceitação pelos consumidores do atributo aparência do lombo suíno (cru) embalado a vácuo. As embalagens transparentes foram apresentadas em expositor comercial refrigerado $\left(4^{\circ} \mathrm{C} \pm 1\right)$, que simulava a gôndola do supermercado. Os mesmos consumidores avaliaram a aceitação do lombo suíno grelhado quanto aos atributos aparência, odor, textura, sabor e impressão global, bem como quanto à intenção de compra.

Foi utilizada a escala hedônica estruturada mista de 9 pontos para avaliação da aceitação dos atributos aparência, odor, textura, sabor e impressão global, em que: 9, gostei muitíssimo; 5, nem gostei nem desgostei; e 1, desgostei muitíssimo. Para a intenção de compra, foi utilizada a escala de 5 pontos, em que: 1 , certamente não compraria este produto; 3 , talvez comprasse, talvez não comprasse; e 5 , certamente compraria este produto. Foram servidos aos consumidores dois pedaços de lombo grelhado $(2,0 \times 2,0 \times 2,5 \mathrm{~cm})$ referentes a cada tratamento, codificados com número de três dígitos. Os tratamentos foram apresentados aos consumidores de forma monádica, com uso de blocos completos balanceados para evitar o efeito de contraste e da ordem de apresentação dos tratamentos (Stone \&
Sidel, 1993). Foram oferecidas água e bolacha sem sal para a limpeza do palato entre as amostras. As análises sensoriais foram realizadas em cabines individuais equipadas com computadores. Os resultados foram coletados por meio do programa Compusense Five, versão 4.25 (Compusense Inc., Guelph, Ontario, Canada).

Utilizou-se o delineamento experimental inteiramente casualizado em arranjo fatorial $3 \times 2$, com a condição sexual (FE, CF e IM) e a dieta (CON e RAC) como efeitos fixos. Avaliou-se a interação entre os dois tratamentos, com o modelo estatístico: $\mathrm{Y}_{\mathrm{ijk}}=\mu+\tau_{\mathrm{i}}+\beta_{\mathrm{j}}+(\tau \beta)_{\mathrm{ij}}+\varepsilon_{\mathrm{ijk}}$, em que $\mathrm{Y}_{\mathrm{ijk}}$ é o valor da variável de qualidade do lombo na condição sexual $\mathrm{i}$, suplementado com nível de RAC j, na k-ésima repetição; $\mu$ é uma constante (média geral); $\tau_{\mathrm{i}}$ é o efeito da condição sexual $\mathrm{i} ; \beta_{\mathrm{j}}$ é o efeito da suplementação com RAC j; $(\tau \beta)_{\mathrm{ij}}$ é o efeito da interação entre $\tau_{\mathrm{i}}$ e $\beta_{\mathrm{j}}$; e $\varepsilon_{\mathrm{ijk}}$ é o componente do erro aleatório residual.

Os resultados foram submetidos à análise de variância sob o método de máxima verossimilhança (REML), por meio do procedimento Proc Mixed do programa SAS 9.2 (SAS Institute Inc., Cary, NC, EUA). Os resíduos atenderam às pressuposições de normalidade e homogeneidade de variância. Os tratamentos e as interações cujo efeito foi significativo pelo teste $\mathrm{F}$, a $5 \%$ de probabilidade, tiveram suas médias analisadas por meio do teste de Tukey, também a 5\% de probabilidade.

\section{Resultados e Discussão}

Não houve interação entre condição sexual e uso de ractopamina nas características de qualidade do lombo suíno cru, nem nos parâmetros $\mathrm{pH}$, textura instrumental (força de cisalhamento) e cor instrumental ( $\mathrm{L}^{*}, \mathrm{a}^{*}, \mathrm{~b}^{*}$, croma e matiz); portanto, apenas os efeitos principais são apresentados (Tabela 1).

$\mathrm{O}$ pH do lombo suíno cru 24 horas após o abate $\left(\mathrm{pH}_{24 \mathrm{~h}}\right)$ foi semelhante entre as condições sexuais com ou sem ractopamina. Xiong et al. (2006) também encontraram valores de $\mathrm{pH}_{24 \mathrm{~h}}$ semelhantes, de 5,39 e 5,38 , respectivamente, em suínos fêmeas e em machos castrados fisicamente alimentados com $(20 \mathrm{ppm})$ ou sem ractopamina na dieta de terminação. Do mesmo modo, outros autores também não observaram diferença no $\mathrm{pH}_{24 \mathrm{~h}}$ de longissimus dorsi entre suínos castrados fisicamente e em fêmeas com ou sem ractopamina na dieta (Gispert et al., 2010; Hinson 
et al., 2011; Kutzler et al., 2011; Athayde et al., 2012). No entanto, Carr et al. (2005) relataram maiores valores de $\mathrm{pH}$ em longissimus dorsi de suínos alimentados com ractopamina.

Em relação à condição sexual, animais castrados fisicamente tiveram lombos mais macios, seguidos das fêmeas e dos imunocastrados, em decorrência do maior teor de lipídeo intramuscular normalmente encontrado em animais castrados fisicamente. A adição de ractopamina na dieta aumentou a força de cisalhamento nos lombos crus em relação ao controle (Tabela 1). Outros autores também constataram valores de força de cisalhamento mais elevados em carne de suínos alimentados com ractopamina (Xiong et al., 2006; Fernández-Dueñas et al., 2008; Leonardo, 2008; Athayde et al., 2012). A ractopamina altera a proporção de fibras musculares, em especial a miosina de cadeia pesada; e o efeito de repartição induzida por agonistas $\beta$-adrenérgicos é, em parte, mediado pela alteração da expressão de genes específicos para o tipo de fibra muscular, por meio do receptor B (Gunawan et al., 2007). Essas modificações alteram a qualidade da carne, especialmente a maciez, pois a ractopamina age sobre a expressão de isoformas de calpastatina (Leonardo, 2008), um inibidor natural do processo de amaciamento da carne, o que reduz a maciez pela diminuição da proteólise post mortem (Xiong et al., 2006).

Os parâmetros de cor instrumental não diferiram entre as condições sexuais e a ractopamina para carne crua (Tabela 1). Fernández-Dueñas et al. (2008) e Boler et al. (2011) também concluíram que não houve diferença nos parâmetros $L^{*}, a^{*}$ e b* entre o músculo semimembranosus de suínos alimentados com ou sem ractopamina. Athayde et al. (2012) encontraram diferença apenas para o teor de vermelho $\left(a^{*}\right)$ entre longissimus dorsi de suínos que consumiram ou não ractopamina na dieta.

Não houve efeito da condição sexual nem da ractopamina no rendimento com processamento por injeção e na perda de peso por exsudação dos lombos suínos (Tabela 2), o que mostra que, para esse híbrido comercial, a condição sexual e a suplementação com ractopamina na dieta não influenciam a retenção de água injetada no interior da carne. Houve efeito entre as condições sexuais para a variável perda de peso por cocção, em que os imunocastrados tiveram menor perda de peso após o cozimento, o que pode promover a manutenção da suculência e da maciez, enquanto as fêmeas tiveram a maior perda. A condição sexual influenciou a redução da perda de perda de peso por cocção de lombos injetados com salmoura com tripolifosfato. Sheard et al. (1999), ao avaliar a qualidade de lombos marinados com $5 \%$ de tripolifosfato na salmoura (bifes grelhados até $72,5^{\circ} \mathrm{C}$ ), observaram que os dos machos apresentaram menor perda de peso por cocção que os das fêmeas, provavelmente pelo maior teor de proteínas miofibrilares naturalmente presente nos machos.

O aprimoramento na suculência e na maciez de carnes processadas por injeção de salmoura decorre da propriedade de retenção de água da carne. Os ingredientes utilizados modificam a estrutura miofibrilar, em especial o tripolifosfato, pois se ligam às proteínas miofibrilares, o que aumenta a repulsão de cargas entre os miofilamentos e facilita a remoção de proteínas miofibrilares transversais que

Tabela 1. Efeito da condição sexual (CS) e da adição de ractopamina (RAC) na dieta sobre pH, cor e textura instrumental no lombo suíno $\mathrm{cru}^{(1)}$.

\begin{tabular}{|c|c|c|c|c|c|c|c|c|c|}
\hline \multirow[t]{2}{*}{ Parâmetro } & \multicolumn{3}{|c|}{ Condição sexual (2) $^{(2)}$} & \multicolumn{2}{|c|}{ Ractopamina } & \multirow{2}{*}{$\begin{array}{l}\text { CV } \\
(\%)\end{array}$} & \multicolumn{3}{|c|}{ Valor $\mathrm{p}$} \\
\hline & FE & $\mathrm{CF}$ & IM & 0 & $7,5 \mathrm{ppm}$ & & $\mathrm{CS}$ & RAC & CS $x$ RAC \\
\hline$\overline{\mathrm{pH}_{24 \mathrm{~h}}{ }^{(3)}}$ & 5,38 & 5,37 & 5,37 & 5,36 & 5,39 & 1,26 & 0,91 & 0,19 & 0,83 \\
\hline Maciez $\left(\mathrm{kgf} \mathrm{cm}^{-2}\right)$ & $3,50 \mathrm{ab}$ & $3,30 \mathrm{~b}$ & $3,68 b$ & $3,37 b$ & $3,62 \mathrm{a}$ & 13,51 & 0,04 & 0,04 & 0,92 \\
\hline $\mathrm{L}^{*}$ & 47,88 & 48,39 & 47,78 & 48,02 & 48,01 & 4,46 & 0,82 & 0,99 & 0,95 \\
\hline$a^{*}$ & 6,85 & 7,30 & 7,38 & 7,26 & 7,09 & 12,39 & 0,37 & 0,59 & 0,26 \\
\hline$b^{*}$ & 0,94 & 1,62 & 1,41 & 1,42 & 1,22 & 73,45 & 0,32 & 0,58 & 0,65 \\
\hline Croma & 6,91 & 7,48 & 7,51 & 7,40 & 7,19 & 13,65 & 0,36 & 0,68 & 0,29 \\
\hline $\operatorname{Matiz}\left(\mathrm{h}^{\circ}\right)$ & 7,81 & 12,51 & 10,82 & 11,07 & 9,76 & 69,22 & 0,40 & 0,53 & 0,61 \\
\hline
\end{tabular}

${ }^{(1)}$ Médias seguidas de letras iguais, na linha, não diferem pelo teste de Tukey, a 5\% de probabilidade. (2)FE, fêmea; CF, macho castrado fisicamente; e IM, macho imunocastrado. ${ }^{(3)} \mathrm{pH}_{24 \mathrm{~h}} \mathrm{pH}$ do lombo suíno cru 24 horas após o abate; e $\mathrm{kgf} \mathrm{cm}^{-2}$, avaliação de textura instrumental pela força de cisalhamento do lombo cru. 
podem atuar como restrições estruturais à extração da miosina. A expansão dos miofilamentos reticulados permite que a água injetada se ligue por força iônica e forme uma matriz de gel viscoelástico que contribui para manutenção da água no interior da carne (Xiong, 2005).

$\mathrm{Na}$ análise da composição centesimal, houve efeito da ractopamina no teor de umidade dos lombos processados (Tabela 2). Os tratamentos da dieta controle $(\mathrm{CON})$ tiveram maior umidade que os com ractopamina. Houve interação de condição sexual e ractopamina apenas para os teores de lipídeos. O tratamento CF-CON apresentou maior teor lipídico de 3,39\%, enquanto IM-CON e FE-CON apresentaram teores semelhantes, de 2,56 e 2,02\%, respectivamente. Nas amostras de lombo, provenientes de suínos que receberam suplementação com ractopamina, houve efeito diferenciado: FE-RAC (4,85\%) apresentou a maior percentagem lipídica; já IM-RAC $(3,70 \%)$ e CF-RAC (3,78\%) apresentaram teores semelhantes.

Em linhagens genéticas desenvolvidas para maior deposição de carne, as fêmeas respondem melhor à ractopamina que os machos castrados (Amaral et al., 2009), uma vez que apresentam maior quantidade de lipídeos e capacidade de mobilizá-los; a diminuição de lipídeos é evidente principalmente no tecido adiposo subcutâneo e irrisório no tecido adiposo intramuscular (Engeseth et al., 1992). Contudo, o híbrido comercial avaliado no presente trabalho, desenvolvido para maior resistência imunológica e alta prolificidade, parece não responder da mesma maneira à suplementação com ractopamina.

Caldara et al. (2013) avaliaram a qualidade de lombo suíno de fêmeas, machos castrados fisicamente e imunocastrados, e não encontraram diferença nos teores de proteína, umidade e lipídeos. Boler et al. (2011) relataram interação de ractopamina e condição sexual no teor de proteína no presunto cozido, e efeito de ractopamina no teor de lipídeos. De forma semelhante, Tavárez et al. (2012), ao avaliar cortes dianteiros para produção de bacon e copa, observaram, em bacon, diferença entre ractopamina e condição sexual nos teores de umidade e lipídeos, além de efeito da condição sexual na proteína; e, em copa, interação entre ractopamina e condição sexual nos lipídeos, com efeito de condição sexual na umidade e ausência de efeito na proteína. Costa-Lima et al. (2014), ao estudar salsichas cozidas, verificaram efeito de ractopamina no teor de proteína, além de interação entre condição sexual e ractopamina nos lipídeos e na umidade. Esses autores demonstraram que a composição centesimal varia de acordo com o corte utilizado como matéria-prima, bem como com o tipo de processamento e a linhagem genética avaliados.

Os tratamentos IM-CON e CF-CON apresentaram maiores valores de $\mathrm{pH}$ final, após equalização dos lombos processados, quando comparados ao FE-CON (Tabela 3). O pH final dos tratamentos com ractopamina foi diferente, em que FE-RAC apresentou pH superior, seguido de CF-RAC e IM-RAC. A elevação de $\mathrm{pH}$ em carnes oriundas de suínos alimentados com ractopamina é controversa; porém, o aumento de $\mathrm{pH}$ em carnes melhoradas por injeção é natural, uma vez que a salmoura de injeção aplicada apresenta $\mathrm{pH}$ alcalino $(8,4)$, por conter tripolifosfato de sódio. Isso desloca o ponto isoelétrico, o que favorece a retenção de água natural ou injetada no interior da carne (Tabelas 1 e 3 ).

Tabela 2. Efeito da condição sexual (CS) e da adição de ractopamina (RAC) na dieta sobre os parâmetros de rendimento, perda de peso por exsudação (PPE), perda de peso por cocção (PPC) e composição centesimal dos lombos suínos processados com tripolifosfato de sódio e sal ${ }^{(1)}$.

\begin{tabular}{|c|c|c|c|c|c|c|c|c|c|}
\hline \multirow[t]{2}{*}{ Parâmetro } & \multicolumn{3}{|c|}{ Condição sexual(2) $^{(2)}$} & \multicolumn{2}{|c|}{ Ractopamina } & \multirow{2}{*}{$\begin{array}{l}\text { CV } \\
(\%)\end{array}$} & \multicolumn{3}{|c|}{ Valor $\mathrm{p}$} \\
\hline & $\mathrm{FE}$ & $\mathrm{CF}$ & IM & 0 & $7,5 \mathrm{ppm}$ & & $\mathrm{CS}$ & RAC & CS x RAC \\
\hline Rendimento (\%) & 88,01 & 87,84 & 88,30 & 87,65 & 88,45 & 1,78 & 0,17 & 0,80 & 0,30 \\
\hline PPE (\%) & 0,58 & 0,57 & 0,76 & 0,66 & 0,61 & 4,61 & 0,54 & 0,76 & 0,82 \\
\hline PPC (\%) & $22,35 \mathrm{a}$ & $20,51 \mathrm{ab}$ & $18,84 \mathrm{~b}$ & 20,01 & 21,12 & 14,59 & 0,04 & 0,31 & 0,66 \\
\hline Proteína (\%) & 19,42 & 20,51 & 20,01 & 19,91 & 20,05 & 7,02 & 0,33 & 0,81 & 0,43 \\
\hline Lipídeos (\%) & 3,44 & 3,59 & 3,13 & 2,66 & 4,11 & 5,04 & 0,001 & 0,001 & 0,001 \\
\hline Umidade (\%) & 74,46 & 74,19 & 74,70 & $74,81 \mathrm{a}$ & $74,09 \mathrm{~b}$ & 1,03 & 0,33 & 0,02 & 0,27 \\
\hline
\end{tabular}

${ }^{(1)}$ Médias seguidas de letras iguais, na linha, não diferem pelo teste de Tukey, a $5 \%$ de probabilidade. ${ }^{(2)} \mathrm{FE}$, fêmea; $\mathrm{CF}$, macho castrado fisicamente; e IM, macho imunocastrado. 
A luminosidade $\left(\mathrm{L}^{*}\right)$ do lombo suíno processado foi influenciada pela adição de ractopamina na dieta, em que IM-RAC e CF-RAC apresentaram maior luminosidade, e FE-RAC, lombos mais escuros (Tabela 3). Isso pode ser explicado pelo fato de que os polifosfatos e de que o sal presentes na salmoura quelarem os íons metálicos, como o ferro, contidos na mioglobina, e, assim, alterarem a coloração de músculos injetados, com escurecimento da carne (Sheard et al., 2005). Os tratamentos IM-RAC, CF-RAC e FE-RAC tiveram valores de a* semelhantes. Apesar de IM-RAC ter apresentado índice de saturação de vermelho (croma) abaixo dos demais tratamentos com ractopamina, esta suplementação na dieta de terminação uniformizou a tonalidade $\left(\mathrm{h}^{\circ}\right)$ dos cortes nas diferentes condições sexuais. Entretanto, nos tratamentos IM-CON e FE-CON, foram encontrados lombos mais avermelhados $\left(\mathrm{a}^{*}\right.$, croma e $\left.^{\circ}\right)$, e em CF-CON, lombos mais amarelados $\left(b^{*} e h^{\circ}\right)$. A imunocastração favorece o crescimento anabólico natural, o que promove maior deposição de carne magra. Esse resultado pode ser atribuído ao metabolismo glicolítico - diretamente ligado ao teor de mioglobina e do $\mathrm{pH}$, o que influencia a capacidade de resposta à ractopamina - das fibras intermediárias que apresentam diferenças na tonalidade da cor $\left(\mathrm{h}^{\circ}\right)$.

Quanto ao efeito da interação entre condição sexual e ractopamina na textura instrumental, o tratamento FE-CON apresentou a maior força de cisalhamento, seguido de CF-CON; já IM-CON foi o tratamento com maior maciez (Tabela 3). Entre IM-RAC, CF-RAC e FE-RAC, os valores de força de cisalhamento foram semelhantes, uma vez que a ractopamina uniformizou a maciez dos cortes. O processamento promoveu a diminuição da força de cisalhamento dos lombos suínos para todos os tratamentos, exceto para IM. Segundo Bridi \& Silva (2009), cortes com força de cisalhamento menores que 3,2 kgf são considerados macios; assim, pode-se afirmar que o processamento equalizou a maciez entre os tratamentos.

Todos os tratamentos apresentaram contagem microbiológica inferior ao limite permitido pela legislação, com ausência de Salmonella sp. Foram obtidos: resultado negativo para Staphylococcus sp. coagulase-positiva; contagem de coliformes totais de 3,04 ( $\log$ NMP $\mathrm{g}^{-1}$ ); e coliformes termotolerantes a $45^{\circ} \mathrm{C}$ com contagem inferior a $<0,48$ Log NMP g-1, o que indica boas práticas de manipulação durante o processamento de industrialização e armazenamento.

$\mathrm{Na}$ avaliação sensorial, 93,55\% dos consumidores declararam ser consumidores assíduos de carne suína; destes, $42 \%$ afirmaram consumi-la semanalmente; e $35,48 \%$, que a carne mais consumida é o lombo. Houve efeito da interação de condição sexual e ractopamina na aparência e no odor do lombo suíno grelhado na análise de variância; contudo, essa diferença não foi observada na análise de comparação de médias pelo teste de Tukey, a 5\% de probabilidade, para condição sexual e dieta (Tabela 4). Quando questionados quanto à intenção de compra, os consumidores informaram que provavelmente comprariam a carne proveniente do tratamento CF-CON $(4,19)$, tendo sido indiferentes para FE-CON $(3,16)$ e IM-CON $(3,32)$. Entre os tratamentos IM-RAC, CF-RAC e FE-RAC, não houve diferença.

Conforme Sheard et al. (1999), em análise sensorial feita com lombos marinados com 5\% de tripolifosfato, os julgadores relataram que as fêmeas apresentaram

Tabela 3. Efeito da condição sexual (CS) e da adição de 7,5 ppm de ractopamina (RAC) na dieta sobre pH, após 72 horas de equalização, cor e textura instrumental dos lombos suínos processados com tripolifosfato de sódio e sal ${ }^{(1)}$.

\begin{tabular}{|c|c|c|c|c|c|c|c|c|c|c|}
\hline \multirow[t]{2}{*}{ Parâmetro } & \multicolumn{3}{|c|}{ Controle $^{(2)}$} & \multicolumn{3}{|c|}{ Ractopamina } & \multirow{2}{*}{$\begin{array}{l}\text { CV } \\
(\%)\end{array}$} & \multicolumn{3}{|c|}{ Valor $\mathrm{p}$} \\
\hline & $\mathrm{FE}$ & $\mathrm{CF}$ & IM & $\mathrm{FE}$ & $\mathrm{CF}$ & IM & & $\mathrm{CS}$ & RAC & $\mathrm{CS} \times \mathrm{RAC}$ \\
\hline$\overline{\mathrm{pH}}$ & $5,67 \mathrm{c}$ & $5,79 \mathrm{~b}$ & $5,75 b$ & $5,9 a$ & $5,75 b$ & $5,67 \mathrm{c}$ & 1,50 & $<0,0001$ & 0,0030 & $<0,0001$ \\
\hline Maciez $\left(\mathrm{kgf} \mathrm{cm}^{-2}\right)^{(3)}$ & 2,96ab & $2,74 \mathrm{~b}$ & $2,19 \mathrm{c}$ & $2,88 \mathrm{ab}$ & $3,07 \mathrm{ab}$ & $3,30 \mathrm{a}$ & 17,36 & 0,2515 & $<0,0001$ & $<0,0001$ \\
\hline $\mathrm{L}^{*}$ & $40,68 b$ & $43,80 \mathrm{a}$ & $37,38 \mathrm{c}$ & $36,76 \mathrm{c}$ & $38,63 \mathrm{bc}$ & $40,95 b$ & 6,49 & 0,0001 & 0,0009 & $<0,0001$ \\
\hline$a^{*}$ & $3,71 \mathrm{ab}$ & $2,39 \mathrm{a}$ & $4,60 \mathrm{a}$ & $4,64 \mathrm{a}$ & $3,90 \mathrm{ab}$ & $3,39 \mathrm{a}$ & 22,25 & 0,001 & 0,0258 & $<0,0001$ \\
\hline$b^{*}$ & $1,51 \mathrm{a}$ & $1,97 \mathrm{a}$ & $1,30 \mathrm{~b}$ & $1,19 b$ & $1,24 b$ & $1,66 \mathrm{a}$ & 27,07 & 0,45 & 0,1666 & 0,0464 \\
\hline Croma & $4,01 \mathrm{abc}$ & $3,10 \mathrm{c}$ & $4,78 \mathrm{a}$ & $4,79 \mathrm{a}$ & $4,09 \mathrm{ab}$ & $3,77 b c$ & 16,24 & 0,003 & 0,1375 & 0,0004 \\
\hline Matiz $\left(\mathrm{h}^{\circ}\right)$ & $22,15 b$ & $39,5 c$ & $15,78 \mathrm{~b}$ & $14,38 b$ & $17,64 b$ & $26,09 \mathrm{ab}$ & 34,45 & 0,014 & 0,0211 & 0,0006 \\
\hline
\end{tabular}

${ }^{(1)}$ Médias seguidas de letras iguais, na linha, não diferem pelo teste de Tukey, a $5 \%$ de probabilidade. ${ }^{(2)}$ Controle, sem adição de ractopamina. ${ }^{(3)} \mathrm{kgf} \mathrm{cm}^{-2}$, avaliação de textura instrumental pela força de cisalhamento do lombo cru. FE, fêmea; CF, macho castrado fisicamente; e IM, macho imunocastrado. 
Tabela 4. Efeito da condição sexual (CS) e da adição de 7,5 ppm de ractopamina (RAC) nos atributos sensoriais dos lombos suínos processados com tripolifosfato de sódio e sal ${ }^{(1)}$.

\begin{tabular}{|c|c|c|c|c|c|c|c|c|c|c|}
\hline \multirow[t]{2}{*}{ Atributo } & \multicolumn{3}{|c|}{ Controle $^{(2)}$} & \multicolumn{3}{|c|}{ Ractopamina } & \multirow{2}{*}{$\begin{array}{l}\text { CV } \\
(\%)\end{array}$} & \multicolumn{3}{|c|}{ Valor $\mathrm{p}$} \\
\hline & FE & $\mathrm{CF}$ & IM & FE & $\mathrm{CF}$ & IM & & $\mathrm{CS}$ & RAC & CS x RAC \\
\hline Aparência ${ }^{(3)}$ & 7,61 & 8,03 & 7,68 & 7,68 & 7,36 & 7,43 & 14,80 & 0,7879 & 0,0858 & 0,1851 \\
\hline Aparência $^{(4)}$ & 6,90 & 7,36 & 7,42 & 7,52 & 7,00 & 6,61 & 19,54 & 0,7034 & 0,3660 & 0,0149 \\
\hline Odor & 6,32 & 7,48 & 6,45 & 6,94 & 6,49 & 6,39 & 26,53 & 0,1940 & 0,5575 & 0,0379 \\
\hline Sabor & 6,10 & 7,36 & 6,00 & 6,52 & 6,81 & 6,42 & 28,34 & 0,0155 & 0,7173 & 0,2346 \\
\hline Textura & 6,58 & 7,42 & 6,74 & 7,19 & 7,42 & 7,00 & 20,73 & 0,0588 & 0,1733 & 0,4979 \\
\hline Aceitação global & 6,16 & 7,26 & 6,16 & 6,87 & 7,03 & 6,61 & 25,14 & 0,0255 & 0,1992 & 0,2674 \\
\hline Intenção de compra & $3,16 b$ & $4,19 a$ & $3,32 b$ & $3,77 \mathrm{ab}$ & $3,87 \mathrm{ab}$ & $3,52 \mathrm{ab}$ & 28,62 & 0,0009 & 0,2708 & 0,0344 \\
\hline
\end{tabular}

${ }^{(1)}$ Médias seguidas de letras iguais, na linha, não diferem pelo teste de Tukey, a $5 \%$ de probabilidade. ${ }^{(2)}$ Controle, sem adição de ractopamina. ${ }^{(3)}$ Aparência do lombo suíno processado cru embalado a vácuo. ${ }^{(4)}$ Aparência do lombo suíno processado grelhado. FE, fêmea; CF, macho castrado fisicamente; e IM, macho imunocastrado.

cortes mais macios que os machos. Pauly et al. (2010) não encontraram diferença entre lombos de suínos castrados fisicamente e imunocastrados quanto ao odor, ao sabor e à maciez com equipe treinada. Da mesma forma, Caldara et al. (2013) não obtiveram diferença entre os atributos sensoriais estudados (odor, aparência, maciez e sabor) para lombos oriundos de fêmeas, machos castrados fisicamente e imunocastrados. Há diferenças de características de qualidade da carne entre as condições sexuais; no entanto, no presente trabalho, os consumidores não perceberam essas diferenças entre os atributos sensoriais avaliados.

\section{Conclusões}

1. A suplementação com ractopamina e a imunocastração proporcionam lombos suínos menos macios.

2. Lombos de suínos imunocastrados suplementados com ractopamina e processados com tripolifosfato de sódio e sal apresentam coloração mais vermelha.

3. Diferenças na aparência e na textura dos lombos suínos, independentemente da condição sexual e da ractopamina, não são percebidas pelos consumidores, o que mostra que o processamento padroniza os cortes.

\section{Agradecimentos}

À Coordenação de Aperfeiçoamento de Pessoal de Nível Superior (Capes), pela concessão de bolsa; ao pesquisador Dr. Expedito Tadeu Facco Silveira (in memoriam) do Instituto de Tecnologia de Alimentos (Ital), pela orientação e pela parceria na elaboração do projeto e na condução deste experimento; às empresas Ourofino Saúde Animal e Zoetis, pelo apoio financeiro e pelo fornecimento da ractopamina e do inibidor hormonal Vivax; à Granja comercial Água Branca, por ceder suas instalações e os animais para o experimento; e ao Frigorífico Vangélio Mondelli, pela parceria no abate dos animais.

\section{Referências}

AGÊNCIA NACIONAL DE VIGILÂNCIA SANITÁRIA (Brasil). Resolução RDC no 12, de 2 de janeiro de 2001. Aprova o regulamento técnico sobre padrões microbiológicos para alimentos. Diário Oficial [da] República Federativa do Brasil, 10 jan. 2001. Seção 1, p.54.

AMARAL, N. de O.; FIALHO, E.T.; CANTARELLI, V. de S.; ZANGERONIMO, M.G.; RODRIGUES, P.B.; GIRÃO, L.V.C. Ractopamine hydrochloride in formulated rations for barrows or gilts from 94 to $130 \mathrm{~kg}$. Revista Brasileira de Zootecnia, v.38, p.1494-1501, 2009. DOI: 10.1590/S1516-35982009000800013.

ASSOCIATION OF OFFICIAL ANALYTICAL CHEMISTS. Official methods of analysis of the AOAC International. $16^{\text {th }} \mathrm{ed}$. Washington: AOAC, 1995.

ATHAYDE, N.B.; DALLACOSTA, O.A.; ROÇA, R.O.; GUIDONI, A.L.; LUDTKE, C.B.; LIMA, G.J.M.M. Meat quality of swine supplemented with ractopamine under commercial conditions in Brazil. Journal of Animal Science, v.90, p.4604-4610, 2012. DOI: 10.2527/jas.2012-5102.

BOLER, D.D.; HOLMER, S.F.; DUNCAN, D.A.; CARR, S.N.; RITTER, M.J.; STITES, C.R.; PETRY, D.B.; HINSON, R.B.; ALLEE, G.L.; McKEITH, F.K.; KILLEFER, J. Fresh meat and further processing characteristics of ham muscles from finishing pigs fed ractopamine hydrochloride. Journal of Animal Science, v.89, p.210-220, 2011. DOI: 10.2527/jas.2010-3041.

BRIDI, A.M.; SILVA, C.A. Avaliação da carne suína. Londrina: Midiograf, 2009. 120p.

CALDARA, F.R.; MOI, M.; SANTOS, L.S. dos; PAZ, I.C. de L.A.; GARCIA, R.G.; NÄÄS, I. de A.; FERNANDES, A.R.M. Carcass characteristics and qualititative attributes of pork from immunocastrated animals. Asian-Australasian Journal 
of Animal Sciences, v.26, p.1630-1636, 2013. DOI: 10.5713/ ajas.2013.13160.

CARR, S.N.; RINCKER, P.J.; KILLEFER, J.; BAKER, D.H.; ELLIS, M.; McKEITH, F.K. Effects of different cereal grains and ractopamine hydrochloride on performance, carcass characteristics, and fat quality in late-finishing pigs. Journal of Animal Science, v.83, p.223-230, 2005.

COSTA-LIMA, B.R.C.; CANTO, A.C.V.C.S.; SUMAN, S.P.; CONTE-JUNIOR, C.A.; SILVEIRA, E.T.F.; SILVA, T.J.P. Sex-specific effect of ractopamine on quality attributes of pork frankfurters. Meat Science, v.96, p.799-805, 2014. DOI: 10.1016/j. meatsci.2013.10.001.

ENGESETH, N.J.; LEE, K.-O.; BERGEN, W.G.; HELFERICH, W.G.; KNUDSON, B.K.; MERKEL, R.A. Fatty acid profiles of lipid depots and cholesterol concentration in muscle tissue of finishing pigs fed ractopamine. Journal of Food Science, v.57, p.1060-1062, 1992. DOI: 10.1111/j.1365-2621.1992.tb11262.x.

FERNÁNDEZ-DUEÑAS，D.M.; MYERS，A.J.; SCRAMLIN, S.M.; PARKS, C.W.; CARR, S.N.; KILLEFER, J.; McKEITH, F.K. Carcass, meat quality, and sensory characteristics of heavy body weight pigs fed ractopamine hydrochloride (Paylean). Journal of Animal Science, v.86, p.3544-3550, 2008. DOI: 10.2527/ jas.2008-0899.

GISPERT, M.; ÀNGELS OLIVER, M.; VELARDE, A.; SUAREZ, P.; PÉREZ, J.; FURNOLS, M.F.I. Carcass and meat quality characteristics of immunocastrated male, surgically castrated male, entire male and female pigs. Meat Science, v.85, p.664-670, 2010. DOI: 10.1016/j.meatsci.2010.03.021.

GUNAWAN, A.M.; RICHERT, B.T.; SCHINCKEL, A.P.; GRANT, A.L.; GERRARD, D.E. Ractopamine induces differential gene expression in porcine skeletal muscles. Journal of Animal Science, v.85, p.2115-2124, 2007. DOI: 10.2527/jas.2006-540.

HINSON, R.B.; WIEGAND, B.R.; RITTER, M.J.; ALLEE, G.L.; CARR, S.N. Impact of dietary energy level and ractopamine on growth performance, carcass characteristics, and meat quality of finishing pigs. Journal of Animal Science, v.89, p.3572-3579, 2011. DOI: $10.2527 /$ jas.2010-3302.

HONIKEL, K.O. The water binding of meat. Fleischwirtschaft, v.67, p.1098-1102, 1987.

KUTZLER, L.W.; HOLMER, S.F.; BOLER, D.D.; CARR, S.N.; RITTER, M.J.; PARKS, C.W.; McKEITH, F.K.; KILLEFER, J. Comparison of varying doses and durations of ractopamine hydrochloride on late-finishing pig carcass characteristics and meat quality. Journal of Animal Science, v. 89, p.2176-2188, 2011. DOI: $10.2527 /$ jas.2010-3601.

LANFERDINI, E.; LOVATTO, P.A.; MELCHIOR, R.; ORLANDO, U.A.D.; CECCANTINI, M.; POLEZE, E. Feeding surgically castrated, entire male and immunocastrated pigs with different levels of amino acids and energy at constant protein to energy ratio with or without ractopamine. Livestock Science, v.151, p.246-251, 2013. DOI: 10.1016/j.livsci.2012.11.001.
LEONARDO, E.F. A expressão da isoforma de calpastatina responsiva à ractopamina altera a maciez da carne, com implicações na eficiência de crescimento de suínos. 2008. 64p. Tese (Doutorado) - Escola Superior de Agricultura Luiz de Queiroz, Universidade de São Paulo, Piracicaba.

NATIONAL PORK BOARD. Pork quick facts 2014: stats. Des Moines: NPB, 2014. Available at: <http://www.pork.org/ pork-quick-facts/>. Accessed on: 2 Jan. 2014.

PAULY, C.; SPRING-STAEHLI, P.; O'DOHERTY, J.V.; KRAGTEN, S.A.; DUBOIS, S.; MESSADÈNE, J.; BEE, G. The effects of method of castration, rearing condition and diet on sensory quality of pork assessed by a trained panel. Meat Science, v.86, p.498-504, 2010. DOI: 10.1016/j.meatsci.2010.05.042.

PROJEÇÕES do agronegócio: Brasil 2012/13 a 2022/23: projeções de longo prazo. Brasília: Mapa/ACS, 2013. 96p.

PRUNIER, A.; BONNEAU M.; VON BORELL, E.H.; CINOTTI, S.; GUNN, M.; FREDRIKSEN, B.; GIERSING, M.; MORTON, D.B.; TUYTTENS, F.A.M.; VELARDE, A. A review of the welfare consequences of surgical castration in piglets and evaluation of non-surgical methods. Animal Welfare, v.15, p.277-289, 2006.

RIKARD-BELL, C.; CURTIS, M.A.; VAN BARNEVELD, R.J.; MULLAN, B.P.; EDWARDS, A.C.; GANNON, N.J.; HENMAN, D.J.; HUGHES, P.E.; DUNSHEA, F.R. Ractopamine hydrochloride improves growth performance and carcass composition in immunocastrated boards, intact boars, and gilts. Journal of Animal Science, v.87, p.3536-3543, 2009. DOI: 10.2527/jas.2009-2002.

SHEARD, P.R.; NUTE, G.R.; RICHARDSON, R.I.; PERRY, A.; TAYLOR, A.A. Injection of water and polyphosphate into pork to improve juiciness and tenderness after cooking. Meat Science, v.51, p.371-376, 1999. DOI: 10.1016/S0309-1740(98)00136-3.

SHEARD, P.R.; NUTE, G.R.; RICHARDSON, R.I.; WOOD, J.D. Effects of breed and marination on the sensory attributes of pork from Large White and Hampshire-sired pigs. Meat Science, v.70, p.699-707, 2005. DOI: 10.1016/j.meatsci.2005.03.006.

STONE, H.; SIDEL, J.L. Sensory evaluation practices. $2^{\text {nd }}$ ed. San Diego: Academic Press, 1993. 338p. (Food Science and Technology Series).

TAVÁREZ, M.A.; BOLER, D.D.; CARR, S.N.; RITTER, M.J.; PETRY, D.B.; SOUZA, C.M.; KILLEFER, J.; McKEITH, F.K.; DILGER, A.C. Fresh meat quality and further processing characteristics of shoulders from finishing pigs fed ractopamine hydrochloride (Paylean). Journal of Animal Science, v.90, p.5122-5134, 2012. DOI: 10.2527/jas.2012-5438.

XIONG, Y.L. Role of myofibrillar proteins in water-binding in brine-enhanced meats. Food Research International, v.38, p.281-287, 2005. DOI: 10.1016/j.foodres.2004.03.013.

XIONG, Y.L.; GOWER, M.J.; LI, C.; ELMORE, C.A.; CROMWELL, G.L.; LINDEMANN, M.D. Effect of dietary ractopamine on tenderness and postmortem protein degradation of pork muscle. Meat Science, v.73, p.600-604, 2006. DOI: 10.1016/j.meatsci.2006.02.016.

Recebido em 9 de julho de 2014 e aprovado em 31 de março de 2015

Pesq. agropec. bras., Brasília, v.50, n.5, p.417-425, maio 2015 DOI: $10.1590 / \mathrm{S} 0100-204 X 2015000500009$ 